\title{
THE EFFECTS OF NANO-BIOCHAR ON MAIZE GROWTH IN NORTHERN SHAANXI PROVINCE ON THE LOESS PLATEAU
}

\author{
YANG, Y. $^{1}-$ ZHOU, B. ${ }^{1 *}-\mathrm{HU}, \mathrm{Z}^{1}{ }^{1}-\mathrm{LIN}, \mathrm{H} .{ }^{1,2}$ \\ ${ }^{1}$ State Key Laboratory of Eco-Hydraulics in Northwest Arid Region of China, Xi'an University \\ of Technology, Xi'an 710048, China \\ ${ }^{2}$ Department of Ecosystem Science and Management, The Pennsylvania State University, \\ University Park PA 16802, USA \\ *Corresponding author \\ e-mail: happyangle222@aliyun.com \\ (Received 22 $2^{\text {nd }}$ Oct 2019; accepted $30^{\text {th }}$ Jan 2020)
}

\begin{abstract}
Soil erosion and nutrient loss on the Loess Plateau cause severe desertification and land degradation, which results the loss of soil fertility and grain production. To improve soil quality and grain yield, nano-biochar was banded ( $5 \mathrm{~cm}$ in width, $5 \mathrm{~cm}$ in depth) into a plot $(3 \mathrm{~m} \times 3 \mathrm{~m})$ in Shenmu County, in northern Shaanxi Province on Loess Plateau. The effects of different nano-biochar contents $(0,0.1 \%$, $0.5 \%, 0.7 \%, 1 \%$ in mass) on soil moisture, nutrients, maize growth and yields, were analyzed. The result showed that with increased nano-biochar rates, soil bulk density also increased, and soil aggregates with particle size $>2 \mathrm{~mm}$ increased from 0.69 to $37.12 \%$. At the seedling and shooting stages, soil moisture content in the plots with nano-biochar were significantly higher than those in control. Nano-biochar slowed transport rate of nitrogen from the surface to deeper soil profile. At $0-10 \mathrm{~cm}$ soil depth, the amount of available potassium with nano-biochar applied was higher than those in control plot. The plots with higher nano-biochar content $(0.7 \%$ and $1 \%)$ significantly increased the 1000 -grain weight and yield of maize.
\end{abstract}

Keywords: nano-biochar, growth parameters, 1000-grain weight, maize yields

\section{Introduction}

Northern Shaanxi, China, is large and rich in natural resources. Changes in land use patterns and increasing population have resulted a decrease in the number of grain fields in this area. The remaining farmland is mainly located on slopes, but the plains are suitable for spring maize growth. Rainfall is the main source of water in this region. During the growing period, high rates of evaporation from soil occur due to high solar radiation intensity and high temperature. This results in insufficient water supply for spring maize growth. Previous studies have assessed how changes to management can improve the soil environment, and nutrient and water use efficiency, however, poor soil structure often impedes these efforts (Liu et al., 2012b; Manivasakan et al., 2013; Reese et al., 2014; Zhou et al., 2017, 2018). More research is needed to develop innovative strategies to improve fertilizer use by crops to increase crop yields, enhance plant use of nutrient, and minimize environmental damage.

As a soil amendment, biochar can be used to improve the utilization efficiency of chemical fertilizers and increasing grain yield. High rates (tons per hectare) are often applied, and because soil biochar may be lost via runoff, successfully using biochar to optimize fertilizer strategies may be unpractical. However, researchers have reported that after special treatment, biochar can become nano-biochar, which exists widely in soilvegetation-atmosphere cycling. Due to the large specific surface and small particle size, nano-carbon is easily coupled with nutrient elements and soil microelements to become a 
high-efficiency fertilizer (Roy et al., 2000; Vacher et al., 2003; Mesarič et al., 2013; Guo et al., 2013). Zhou et al. (2018) proposed that nano-biochar could reduce nutrient loss from rainfall-induced erosion on loess slopes under different vegetation cover and concluded that nano-biochar significantly affected soil moisture movement in the Loess Plateau. Wang et al. (2016) found that fertilizer with nano-biochar can increase crop yield by $10 \%$ to $20 \%$, while reducing the amount of fertilizer required by $30 \%$ to $50 \%$.

The objectives of this experiment were to test how banding different nano-biochar concentrations $(0,0.1 \%, 0.5 \%, 0.7 \%, 1 \%)$ affected soil physical and chemical properties, growth characteristics and soil water, and fertilizer utilization efficiency of spring maize crop.

\section{Materials and methods}

\section{Site description}

The experiment was conducted in Liudaogou Village, Xigou Township, Shenmu County, Northern Shaanxi, China (longitude $110^{\circ} 21^{\prime}-110^{\circ} 23^{\prime} \mathrm{E}$, latitude $38^{\circ} 46^{\prime}-$ $\left.38^{\circ} 51^{\prime} \mathrm{N}\right)$. The experimental site was $6.89 \mathrm{~km}^{2}$ in area and situated in an ecologically fragile zone prone of water and wind erosion. The annual mean temperature is $8.4^{\circ} \mathrm{C}$ with the lowest temperature in January and the highest in July. The annual average precipitation is $437.4 \mathrm{~mm}$ and varies from 108.6 to $819.1 \mathrm{~mm}$. (Fu et al., 2015; Jia et al., 2013). The soil types in the basin include aeolian sandy soil and sandic entisols. Poor soil structure is causing serious soil erosion (Wang et al., 2015; Tan et al., 2016). The soil in the test plot is aeolian sandy soil, and the soil physical and chemical properties are shown in Table 1.

\section{Experimental materials and crops}

A local spring maize (the type of maize grown in the region was spring sowing, harvested in autumn, and the region grows only one season of maize so that it is spring maize) was selected in this study. The species of tested maize was Dafeng 30, which came from Shanxi Dafeng Seed Industry Co., Ltd. The tested nano-biochar was a black powder produced by Shanghai Hainuo Carbon Industry Co., Ltd. The nano-biochar diameter was $40 \mathrm{~nm}$, and was carbon powder made of coconut shells, carbonized at high temperature, activated by water vapor and refined by ultrafine grinding at nanometer level. It had rich micropore structure, strong specific surface area and strong absorbability, which can load soil microbes and nutrients. The biochar had a pH of 9.6, a water content of $\leq 5$ and volume density of $0.38 \mathrm{~g} / \mathrm{cm}^{3}$.

\section{Experimental design}

The experiment was performed from March 2016 to July 2018, which have three consecutive growing seasons. The plot size of $3 \mathrm{~m} \times 3 \mathrm{~m}$ was allocated for each treatment. Different concentrations of nano-biochar $(0,0.1 \%, 0.5 \%, 0.7 \%, 1 \%)$ were banded at $5-10 \mathrm{~cm}$ under the soil surface.

The nano-biochar was added to the soil by removing the top $5 \mathrm{~cm}$ of soil, mixing the nano-biochar with soil at $5-10 \mathrm{~cm}$ depth, then replacing the previously removed top $5 \mathrm{~cm}$ of soil. To monitor the water content at different soil depths, five one-meter TRIME pipes were installed at the tested plot. A $3 \mathrm{~m} \times 3 \mathrm{~m}$ protective net was arranged on the periphery of each test plot to prevent farm livestock and wild animals from interfering with the 
plots. The row width and the plant-to-plant distance were $50 \mathrm{~cm}$ and $25 \mathrm{~cm}$. In replicates of two for each treatment, total of 10 experimental plots were established.

Table 1. The soil physical and chemical properties of experimental field

\begin{tabular}{|c|c|c|c|c|c|c|c|c|}
\hline \multirow[b]{2}{*}{ Soil } & \multicolumn{3}{|c|}{ Particle content (\%) } & \multirow{2}{*}{ pH } & \multirow{2}{*}{$\begin{array}{c}\mathrm{CaCO}_{3} \\
(\%)\end{array}$} & \multirow{2}{*}{$\begin{array}{l}\text { Organic } \\
\text { matter } \\
\left(\mathrm{g} \cdot \mathrm{kg}^{-1}\right)\end{array}$} & \multirow{2}{*}{$\begin{array}{c}\text { Total } \\
\text { nitrogen } \\
\left(\mathrm{g} \cdot \mathrm{kg}^{-1}\right)\end{array}$} & \multirow{2}{*}{$\begin{array}{c}\text { Total } \\
\text { phosphorus } \\
\left(\mathbf{g} \cdot \mathbf{k g}^{-1}\right)\end{array}$} \\
\hline & $\begin{array}{c}\text { Clay } \\
(<0.001 \mathrm{~mm})\end{array}$ & $\begin{array}{c}\text { Silt } \\
(0.05-0.001 \mathrm{~mm})\end{array}$ & $\begin{array}{c}\text { Sand } \\
(>0.05 \mathrm{~mm})\end{array}$ & & & & & \\
\hline $\begin{array}{l}\text { Aeolian } \\
\text { sandy soil }\end{array}$ & 15.70 & 37.47 & 46.83 & 8.0 & 4.31 & 5.32 & 0.82 & 0.61 \\
\hline
\end{tabular}

The maize seeds were washed with $10 \% \mathrm{H}_{2} \mathrm{O}_{2}$ for 30 min before sowing. After rinsing with water, the spring maize seeds were soaked in saturated calcium sulfate $\left(\mathrm{CaSO}_{4}\right)$ solution for $4 \mathrm{~h}$, and were transferred to gauze soaked with saturated $\mathrm{CaSO}_{4}$, covered with black plastic film at $25{ }^{\circ} \mathrm{C}$ to accelerate germination. The seeds were sowed after the radicals appeared. Before sowing, nitrogen fertilizer $(\mathrm{N}) 1.458 \mathrm{~kg}$, phosphate fertilizer $\left(\mathrm{P}_{2} \mathrm{O}_{5}\right) 0.874 \mathrm{~kg}$, potassium fertilizer $\left(\mathrm{K}_{2} \mathrm{O}\right) 0.874 \mathrm{~kg}$ were evenly applied in each plot. The field was irrigated before sowing but not after. The sowing depth was $3-5 \mathrm{~cm}$.

\section{Date collection and calculations}

Initial and post-sowing soil nutrients throughout the experiment were measured. The soil moisture characteristic curve was determined by using the $\mathrm{H}-1400 \mathrm{pF}$ soil moisture characteristic curve measurement system produced by Kokusan in Japan. The soil water stable aggregates were determined by a wet sieving apparatus (wet screening device) produced by Eijkelkamp in Netherlands. At different growth stages of maize (seedling stage; shooting stage; tasselling stage; filling stage; and maturation stage), the soil moisture content at different soil depths was measured. Five maize samples (roots, stems and leaves intact) were randomly selected to measure plant nutrients. Soil moisture evapotranspiration in the soil profile was measured by micro-lysimeter. At the same time, five points were randomly selected in each plot to collect soil samples. The plant $\mathrm{N}$ content was determined by the salicylic acid-zinc powder reduction method. The plant phosphorus content was measured by the molybdenum antimony colorimetric method. The plant potassium content was measured by flame photometer. The stem diameter and plant height of the crops was measured by caliper and ruler. After the crop was mature, its production was recorded according to the degranulation of the plot.

The result use Microsoft Excel, IBM Spss10.1 software and Origin function drawing software for statistical analysis, and charting of relevant parameters, single factor variance analysis for significance test (95\% confidence interval).

\section{Results and discussion}

\section{Effects of nano-biochar on the physical and chemical properties}

\section{Effects of nano-biochar on the soil water characteristic curves}

The soil water characteristic curves of eolian sandy soil with different nano-biochar content are shown in Figure 1. Figure 1 shows that under the same soil moisture content, the water suction increased with increasing nano-biochar contents. The soil moisture 
content in soil with higher nano-biochar contents was higher than in lower nano-biochar contents, and the control, at equivalent soil water suction. Similar results regarding nanobiochar effects on soil water capacity have been reported (Fan et al., 2014 and Han et al., 2010). This is because the addition of nano-biochar decreases the number of large pores and increases the number of small pores in the soil. When the suction is applied, the water in the small pores is less affected by the external suction compared with the large pores. The nano-biochar also has a large specific surface area, high surface energy, and a high water retention force. Therefore, nano-biochar has potential to promote root water absorption and improve the water retention of sandy soil.

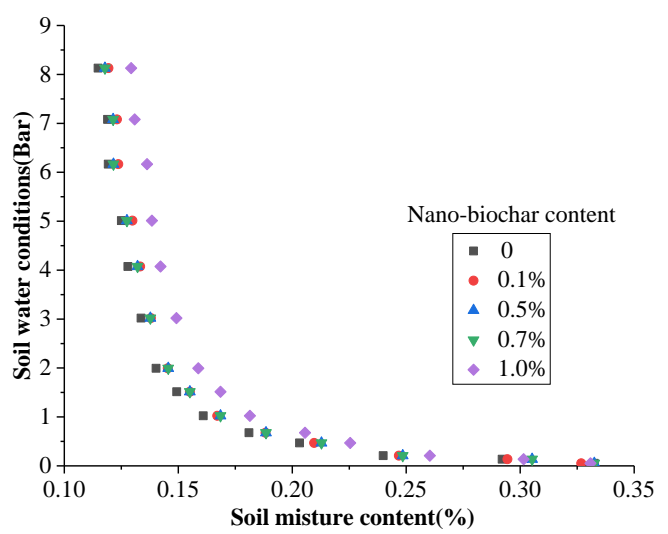

Figure 1. The effect of different nano-biochar content on the soil water characteristics curve

\section{Effect of nano-biochar on soil water stable aggregates}

The influence of nano-biochar application on soil water stable aggregates was determined and the results are presented in Table 2. From Table 2 it was shown that with increases of nano-biochar content in soil, soil aggregates with particle sizes $<0.25 \mathrm{~mm}$ were reduced from 38.21 to $24.33 \%$, while soil aggregates with particle size $>2 \mathrm{~mm}$ increased from 0.69 to $37.12 \%$. The content of soil aggregates with particle size $>2 \mathrm{~mm}$ had the greatest increases with nano-biochar application, showing the ability of nano-biochar to improve soil aggregation. Nano-biochar mass contents of $0.7 \%$ and $1 \%$ had the greatest effects on improving soil water-stable aggregates. Different materials (e.g., minerals, organic matter) with various molecular sizes and chemical characteristics attach to nano-biochar surfaces, and this reduces the nanobiochar's surface area at a molecular scale, thus serving as the binding agents for the formation and stability of soil aggregates (Liang et al., 2006; Bossuyt et al., 2001). The nano-biochar enhanced the formation and stabilization of the soil macroaggregates, especially in sandy loam soil (Six et al., 2004; Liu et al., 2015).

Table 2. The influence of nano-biochar content on the soil water stable aggregate

\begin{tabular}{c|c|c|c|c|c}
\hline $\begin{array}{c}\text { Soil particle size analysis } \\
(\mathbf{m m})\end{array}$ & $\mathbf{0}$ & $\mathbf{0 . 1 0} \%$ & $\mathbf{0 . 5 0 \%}$ & $\mathbf{0 . 7 0 \%}$ & $\mathbf{1 \%}$ \\
\cline { 2 - 5 } & $38.21 \%$ & $33.38 \%$ & $30.48 \%$ & $26.47 \%$ & $24.33 \%$ \\
$0.25 \leq \mathrm{d}<0.5$ & $44.85 \%$ & $40.52 \%$ & $36.14 \%$ & $31.53 \%$ & $28.74 \%$ \\
$0.5 \leq \mathrm{d}<2$ & $16.25 \%$ & $12.96 \%$ & $13.66 \%$ & $11.16 \%$ & $9.81 \%$ \\
$>2$ & $0.69 \%$ & $13.14 \%$ & $19.72 \%$ & $30.84 \%$ & $37.12 \%$ \\
\hline
\end{tabular}




\section{Effects of nano-biochar on water and fertilizer utilization rates of maize}

\section{Effects of nano-biochar on soil moisture content in the soil profile}

The effects of different nano-biochar concentrations on the soil moisture content is shown in Figure 2. From Figure 2 it is shown that the soil moisture content amended with nano-biochar was significantly higher than in the control, especially in the maize seedling and shooting stages. Within $10 \mathrm{~cm}$ of the soil surface, the soil moisture content changed slightly, and it gradually increased with increasing soil depth. At soil depths of 10-30 cm, the soil moisture content increased rapidly. At soil depths of 30$35 \mathrm{~cm}$, soil moisture content gradually stabilized. The surface soils had the lowest soil moisture content because they were affected by high rates of evapotranspiration. With increasing soil depth, the soil moisture content gradually increased. Ouyang et al. (2013) concluded that amending soil with biochar affected the shape of soil water retention curves. Itabari et al. (1993) and Shukla et al. (2012) found that below field capacity, higher soil moisture content in the $0-20 \mathrm{~cm}$ soil layer resulted in faster emergence of maize. Biochar added to soil reduces the number of macro-pores, increases the number of small pores and increases the water-holding capacity of the soil. Ahmed et al. (2018) indicated that biochar amended to soil at rates of $1 \%$ and $3 \%$ increased soil moisture content at field capacity. The results suggest that the application of nano-biochar to soil has potential to greatly improve the water-holding capacity of farmland which may increase the emergence rates of maize.

\section{Effects of nano-biochar on soil nitrate}

Optimal amounts of nitrogen fertilizer to maize crops can promote absorption and use of nitrogen, thereby increasing maize biomass and yield. At the seedling stage of spring maize, the horizontal and vertical distribution of roots is small, root hairs are fine, and root density is sparse. These root characteristics limit the uptake capacity of nitrogen from soil by maize. We observed that the difference between initial and after sowing measurements of soil nitrate were small, and the nitrate content was high (Fig. 3). During the shooting and tasselling stages, the growth and development rate of spring maize increased as the root system increased in size and density. Some of the nitrogen in the soil was absorbed by maize roots and some was transported to the deeper soil layers. These factors resulted in a decrease in soil nitrogen content and greater differences in nitrate between the initial and after sowing measurements. At the grain filling and maturation stages, the growth and development of maize was complete and the rate of nitrogen absorption decreased. The differences in nitrogen between filling and maturation stages were smaller than between the jointing and heading stages. Further analysis of Figure 3 shows that the soil nitrate differences in the plots amended with nano-biochar at rates of $0.7 \%$ and $1 \%$ were smaller than the control group. At the advanced stages of spring maize growth, the differences in nitrate in the soil profile decreased as the nano-biochar contents increased. This indicated that under a consistent crop, the presence of nano-biochar decreases the rate of nitrogen transported to the deep soil (Albiter et al., 2010). Excessive nitrogen application causes the accumulation of nitrate in the soil and increases the risk of nitrate leaching (Zhang et al., 2010). Dempster et al. (2016) found that biochar application increased nitrate adsorption. Therefore, banding nano-biochar at 5-10 cm below the surface can inhibit nitrate leaching and increase nitrogen use efficiency in fertilized soils. 

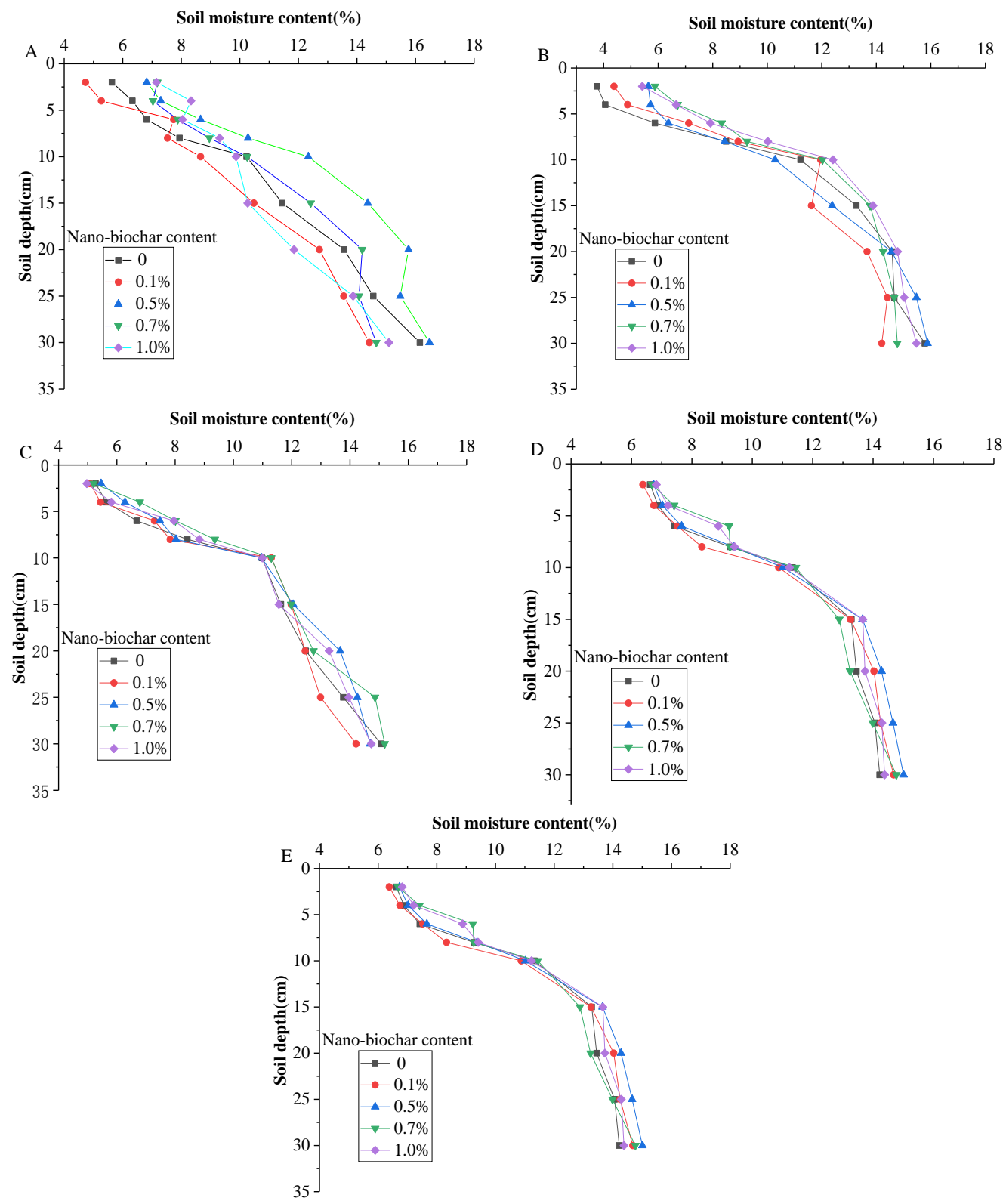

Figure 2. The effect of different nano-biochar content on soil water content: $(A)$ seedling stage; $(B)$ shooting stage; $(C)$ tasselling stage; $(D)$ filling stage; $(E)$ maturation stage

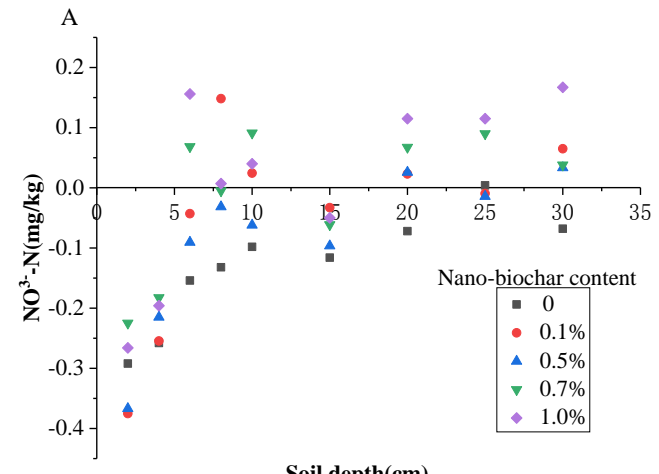

Soil depth(cm)

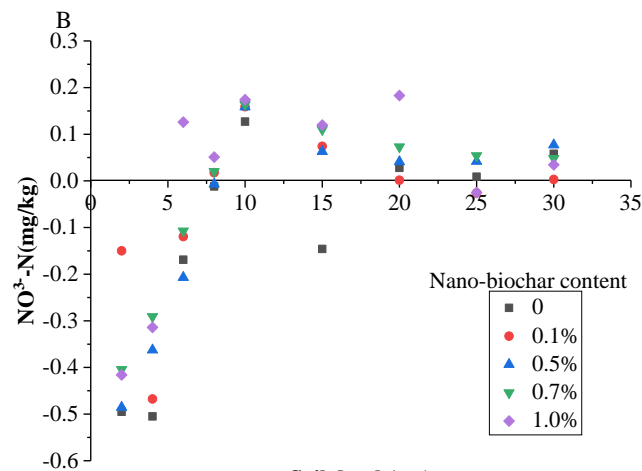

Soil depth(cm) 

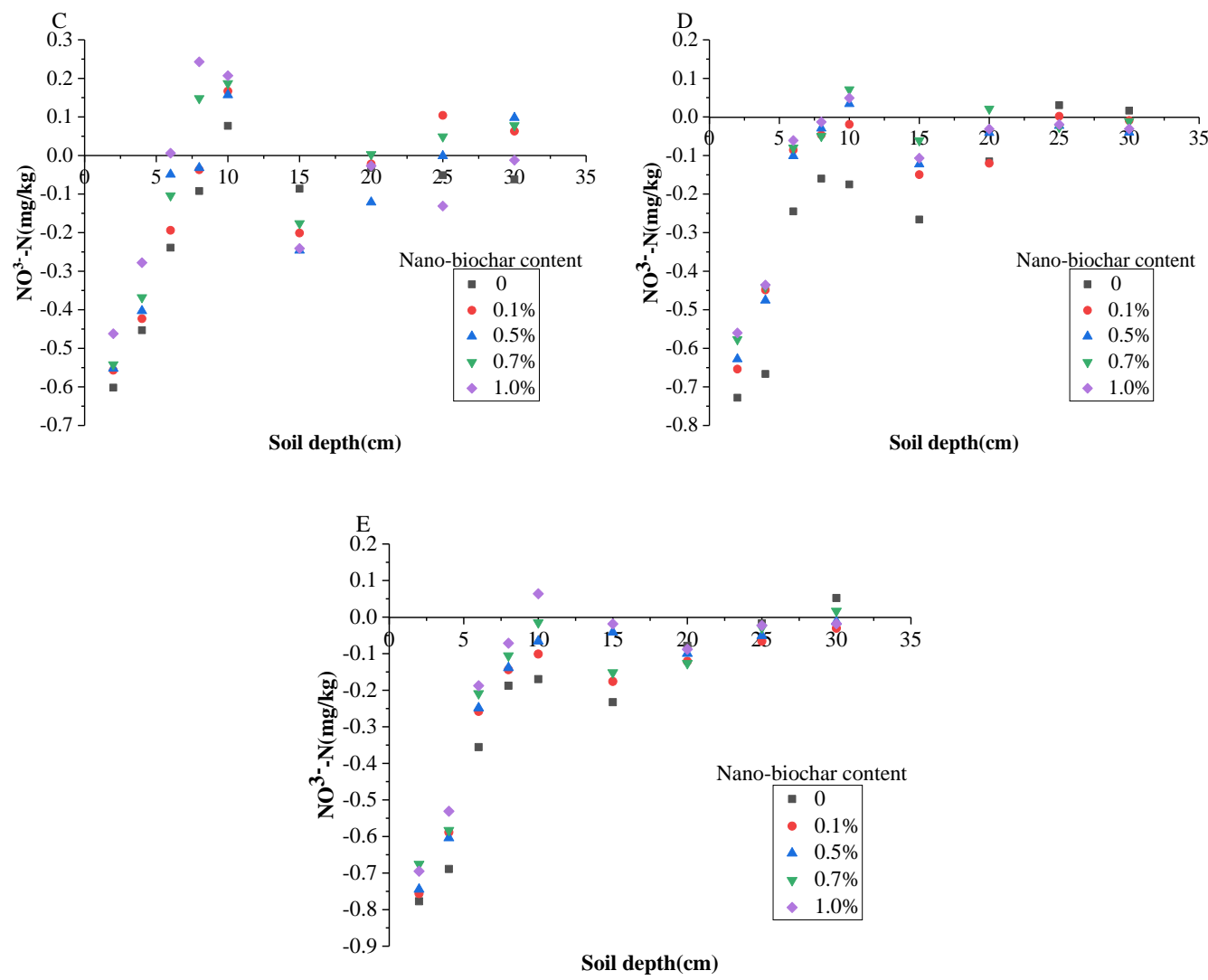

Figure 3. The effect of different nano-biochar content of soil nitrate content: (A) seedling stage; (B) shooting stage; $(C)$ tasselling stage; $(D)$ filling stage; $(E)$ maturation stage

\section{Nano-biochar effects on soil available potassium}

The differences in potassium content in the soil profile at different growth stages of spring maize are shown in Figure 4. At $0-10 \mathrm{~cm}$ soil depth, the amount of available soil potassium in nano-biochar amended soil was higher than in the control. In the 5$10 \mathrm{~cm}$ soil layer, the average available potassium content in soil amended with nanobiochar at rates of $0.7 \%$ and $1 \%$ increased by $11.1 \%$ and $22.6 \%$ compared to the control, respectively, during the tasselling stage. During the early stages of spring maize growth, low amounts of potassium were absorbed by the plants. With the growth and development of spring maize, the uptake of potassium by plant roots gradually increased. At the filling and maturation stages, the growth of spring maize ended and the rate of potassium absorption decreased. Liu et al. (2012a) concluded that when nano-biochar was added to compost, plant-available $\mathrm{Ca}, \mathrm{K}, \mathrm{P}$, and $\mathrm{Na}$ contents increased by a factor of $2.2,2.5,1.2$, and 2.8 , respectively. By increasing the availability of micro-nutrients like potassium in soil, nano-biochar can promote soil fertility (Dong, et al., 2016). When adsorption is poor, available potassium is highly mobile in the soil (Rens et al., 2018). The agglomeration of nano-biochars on soil particles increased the number of small soil pores thus inhibiting the longitudinal migration of potassium ions. This increases the residence time of the available potassium ions in the nano-biochar layer, and ensures high concentrations of potassium ions in the root layer. By doing so, this improves potassium use by spring maize. 

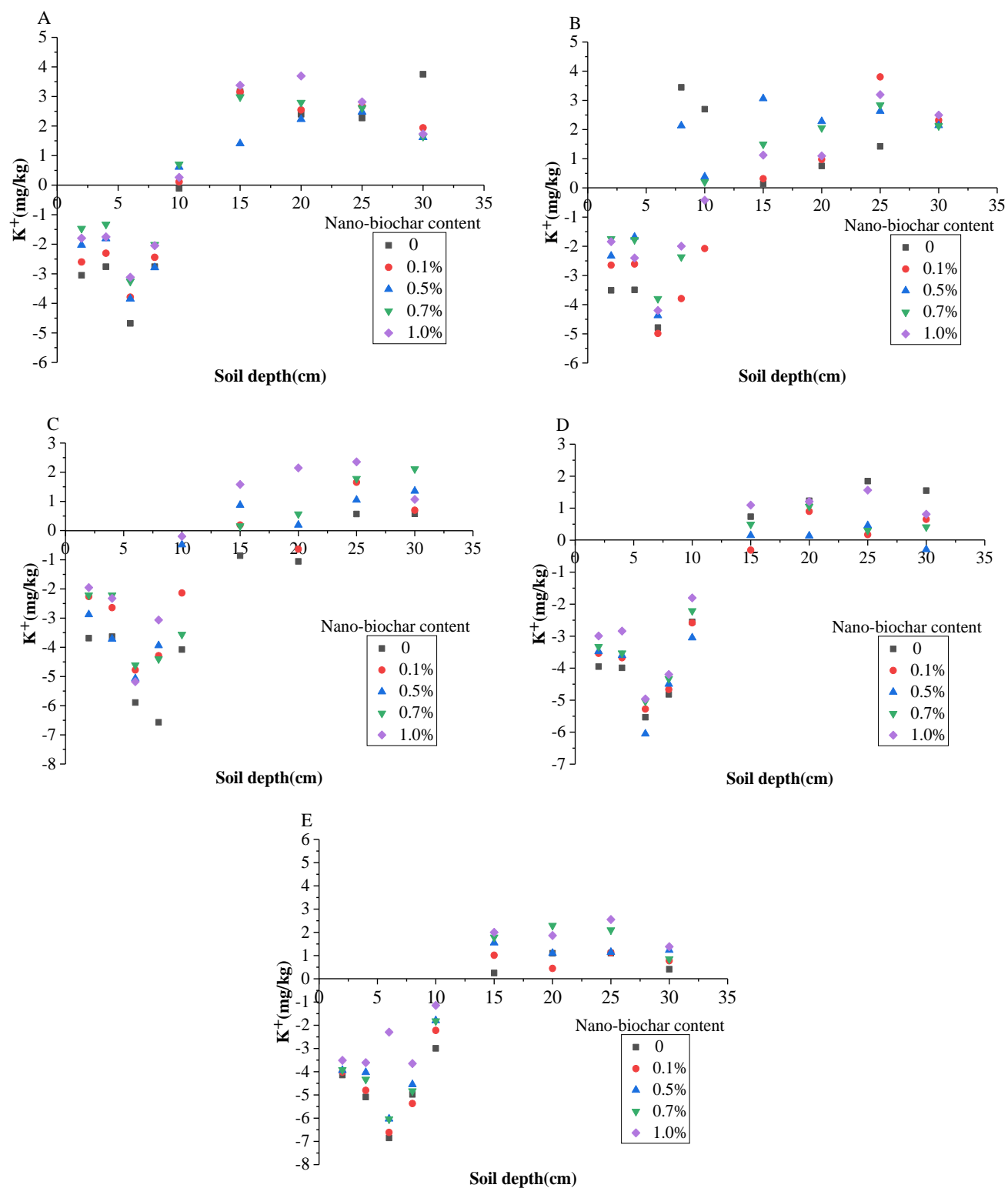

Figure 4. The influence of nano-biochar content on soil potassium content: (A) seedling stage; $(B)$ shooting stage; $(C)$ tasselling stage; $(D)$ filling stage; $(E)$ maturation stage

\section{Nano-biochar effects on soil available phosphorus}

The effects of nano-biochar content on soil available phosphorus in spring maize at different growth periods are shown in Figure 5. Available soil phosphorus concentrations of each treatment were lower in the measurements made after sowing than the initial measurements. There were few differences in soil phosphorus concentrations between each growth period. In the $0-5 \mathrm{~cm}$ soil depth, the differences in soil available phosphorus between the initial and after sowing measurements in nanobiochar amended soil were smaller than in the control group. The variation of the differences between the initial and after sowing soil concentrations decreased with increased nano-biochar concentrations. At $10-35 \mathrm{~cm}$ soil depth, available soil phosphorus variation was low, but the differences in available soil phosphorus initial 
and after sowing measurements in each treatment fluctuated greatly. This suggests that the ability of soil to maintain available phosphorus in the upper layers was greater when soil was banded with nano-biochar, and the ability to regulate available phosphorus in the soil below the carbon layer was limited. In soil, available phosphorus is easily adsorbed by soil particles; phosphorus has strong stability and weak mobility (Sharma et al., 2015; Petr et al., 2011). The soil available phosphorus contents increased with increasing amounts of applied biochar (Arif et al., 2017). Biochar amendments to degraded soils have been shown to improve crop yield and soil quality (Novak et al., 2009). Nano-biochar can significantly improve the inherent soil physical and chemical properties, increasing the proportion of large particles and reducing the soil porosity. A large amount of phosphorus was stabilized in the root zone where nano-biochar was banded because the phosphorus was absorbed to soil particles. This increased the content of phosphorus available for spring maize in the root zone.
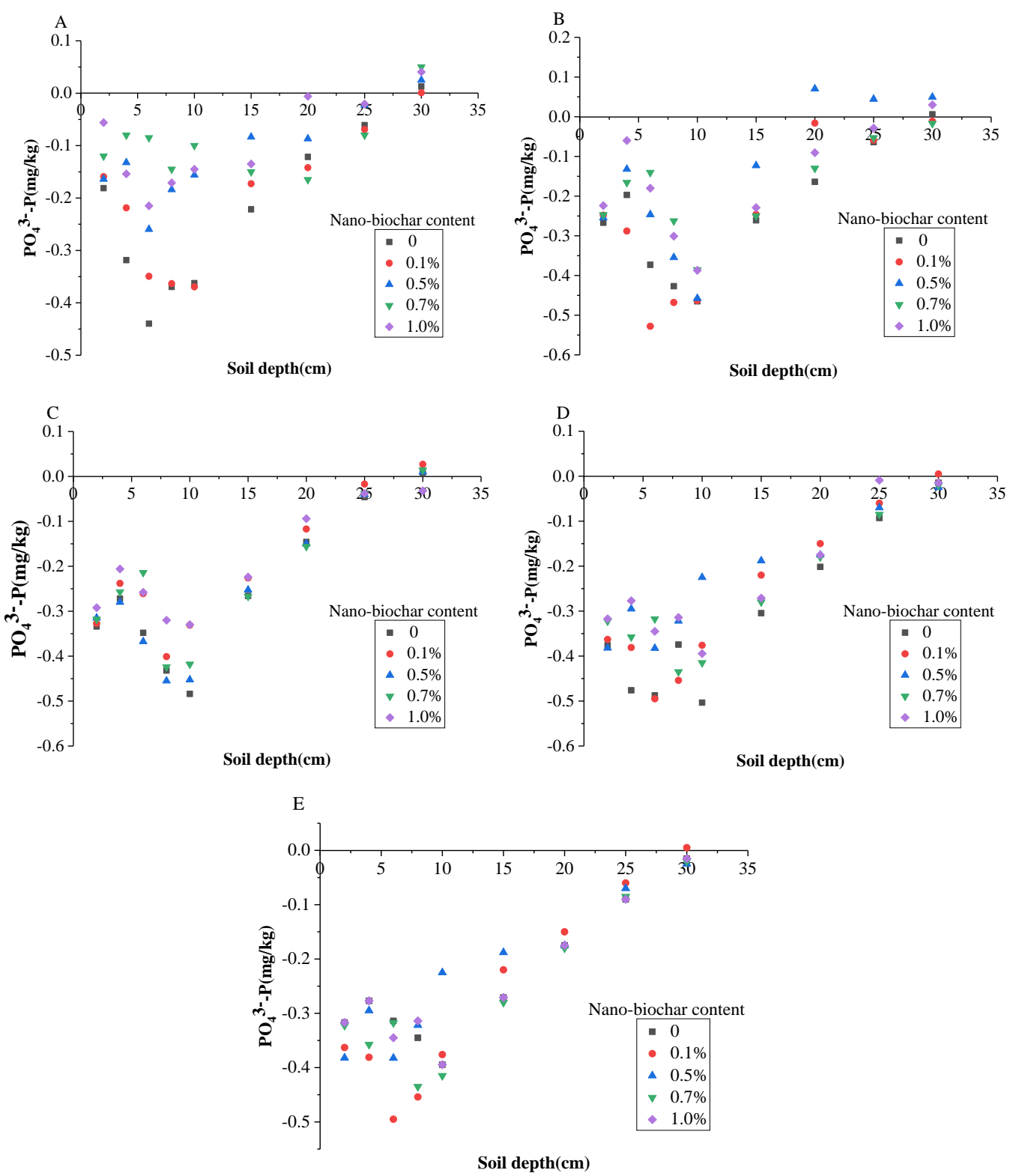

Figure 5. The influence of nano-biochar on soil phosphorus content: (A) seedling stage; (B) shooting stage; $(C)$ tasselling stage; (D) filling stage; (E) maturation stage 


\section{The effects of nano-biochar on growth traits of spring maize}

\section{The effects of nano-biochar on plant nutrients}

The effects of nano-biochar content on spring maize root, stem, leaves and nutrients in each growth period are summarized in Table 3. As shown in Table 3, there is a significant correlation between each factor of different nano-biochar contents; the Pvalue $<0.01$, indicating that each factor has a very significant effect on the test results. Visible, the application of nano-carbon in the soil has an important effect on maize growth. The roots, stems, leaves and other organs had the highest nutrient demand during the shooting stage. Nutrient uptake and accumulation rates in the shooting stage were higher than the tasselling, filling and maturation stages. After the shooting stage, the accumulation of nitrogen, phosphorus and potassium in spring maize plants gradually decreased. Adding nano-biochar to the soil resulted in strong adsorption of nano-biochar to soil nutrients which inhibited the vertical migration of nitrogen. This increased the plant nitrogen concentrations because it promoted nitrogen absorption from the soil by the spring maize, and then nitrogen was transported from the roots to other parts of the plant. Therefore, the spring maize in the nano-biochar amended plots had high concentrations of nitrogen.

Table 3. The influence of nano-biochar content on spring maize nutrient content

\begin{tabular}{|c|c|c|c|c|c|c|c|c|c|c|}
\hline \multirow{2}{*}{$\begin{array}{l}\text { Growth } \\
\text { stages }\end{array}$} & \multirow{2}{*}{$\begin{array}{c}\text { Nano-biochar } \\
\text { content }\end{array}$} & \multicolumn{3}{|c|}{ Leaf $\left(\mathrm{mg} \cdot \mathrm{kg}^{-1}\right)$} & \multicolumn{3}{|c|}{ Stem $\left(\mathbf{m g} \cdot \mathbf{k g}^{-1}\right)$} & \multicolumn{3}{|c|}{$\operatorname{Root}\left(\mathrm{mg} \cdot \mathrm{kg}^{-1}\right)$} \\
\hline & & $\mathbf{N}$ & $\mathbf{P}$ & $\mathbf{K}$ & $\mathbf{N}$ & $\mathbf{P}$ & $\mathbf{K}$ & $\mathbf{N}$ & $\mathbf{P}$ & K \\
\hline \multirow{6}{*}{$\begin{array}{l}\text { Shooting } \\
\text { stage }\end{array}$} & 0 & 23.21 & 1.66 & 30.54 & 26.88 & 1.85 & 36.22 & 18.37 & 1.36 & 38.48 \\
\hline & $0.10 \%$ & 23.28 & 1.69 & 30.88 & 26.84 & 1.93 & 36.28 & 18.41 & 1.33 & 38.41 \\
\hline & $0.50 \%$ & 23.44 & 1.72 & 31.23 & 27.01 & 2.01 & 36.71 & 18.62 & 1.34 & 38.56 \\
\hline & $0.70 \%$ & 23.65 & 1.75 & 31.58 & 27.12 & 2.05 & 36.88 & 18.77 & 1.41 & 39.13 \\
\hline & $1 \%$ & 23.58 & 1.81 & 31.94 & 27.23 & 2.13 & 37.04 & 19.16 & 1.45 & 39.44 \\
\hline & P-value & $3.131 \times 10^{-17}$ & $2.9 \times 10^{-12}$ & $1.74 \times 10^{-14}$ & $3.14 \times 10^{-18}$ & $1.34 \times 10^{-10}$ & $1.68 \times 10^{-16}$ & $1.35 \times 10^{-14}$ & $6.29 \times 10^{-12}$ & $6.48 \times 10^{-16}$ \\
\hline \multirow{6}{*}{$\begin{array}{l}\text { Tasselling } \\
\text { stage }\end{array}$} & 0 & 17.06 & 1.47 & 23.66 & 21.54 & 1.55 & 28.42 & 14.21 & 1.28 & 27.53 \\
\hline & $0.10 \%$ & 17.03 & 1.4 & 23.78 & 21.06 & 1.47 & 27.86 & 14.26 & 1.26 & 27.56 \\
\hline & $0.50 \%$ & 17.15 & 1.39 & 24.15 & 22.13 & 1.53 & 28.19 & 14.98 & 1.24 & 27.68 \\
\hline & $0.70 \%$ & 17.88 & 1.61 & 24.26 & 22.41 & 1.6 & 29.21 & 14.73 & 1.32 & 27.43 \\
\hline & $1 \%$ & 18.13 & 1.65 & 24.37 & 22.68 & 1.63 & 29.48 & 15.09 & 1.38 & 28.11 \\
\hline & P-value & $1.05 \times 10^{-12}$ & $2.16 \times 10^{-9}$ & $1.33 \times 10^{-15}$ & $1.17 \times 10^{-12}$ & $1.22 \times 10^{-11}$ & $1.97 \times 10^{-13}$ & $6.03 \times 10^{-13}$ & $2.11 \times 10^{-11}$ & $1.31 \times 10^{-16}$ \\
\hline \multirow{6}{*}{$\begin{array}{l}\text { Filling } \\
\text { stage }\end{array}$} & 0 & 12.9 & 1.28 & 19.18 & 15.63 & 1.34 & 21.14 & 10.04 & 1.16 & 22.58 \\
\hline & $0.10 \%$ & 12.74 & 1.17 & 19.21 & 15.77 & 1.36 & 21.25 & 10.82 & 1.05 & 22.54 \\
\hline & $0.50 \%$ & 12.86 & 1.31 & 19.28 & 15.86 & 1.38 & 21.36 & 10.66 & 1.18 & 22.87 \\
\hline & $0.70 \%$ & 13.15 & 1.32 & 19.33 & 16.14 & 1.4 & 21.77 & 11.15 & 1.22 & 23.14 \\
\hline & $1 \%$ & 13.23 & 1.38 & 19.45 & 16.47 & 1.47 & 22.06 & 11.33 & 1.26 & 23.65 \\
\hline & P-value & $7.25 \times 10^{-15}$ & $2.99 \times 10^{-10}$ & $1.62 \times 10^{-18}$ & $6.57 \times 10^{-14}$ & $5.26 \times 10^{-12}$ & $1.94 \times 10^{-14}$ & $3.76 \times 10^{-11}$ & $7.85 \times 10^{-10}$ & $4.46 \times 10^{-14}$ \\
\hline \multirow{6}{*}{$\begin{array}{l}\text { Maturation } \\
\text { stage }\end{array}$} & 0 & 8.58 & 1.06 & 13.37 & 11.15 & 1.13 & 16.62 & 7.43 & 1.08 & 15.37 \\
\hline & $0.10 \%$ & 8.68 & 1.11 & 13.41 & 10.98 & 1.18 & 16.48 & 7.56 & 1.14 & 16.18 \\
\hline & $0.50 \%$ & 8.79 & 1.08 & 13.2 & 11.23 & 1.2 & 16.83 & 7.84 & 1.2 & 16.44 \\
\hline & $0.70 \%$ & 9.03 & 1.15 & 13.68 & 11.54 & 1.22 & 17.14 & 7.88 & 1.22 & 16.37 \\
\hline & $1 \%$ & 9.36 & 1.2 & 13.77 & 11.86 & 1.24 & 17.36 & 8.01 & 1.26 & 17.14 \\
\hline & P-value & $4.18 \times 10^{-12}$ & $7.42 \times 10^{-11}$ & $1.48 \times 10^{-14}$ & $1.43 \times 10^{-12}$ & $4.63 \times 10^{-12}$ & $8.23 \times 10^{-14}$ & $1.54 \times 10^{-12}$ & $3.05 \times 10^{-10}$ & $9.37 \times 10^{-12}$ \\
\hline
\end{tabular}

$\mathrm{N}=$ available nitrogen; $\mathrm{P}=$ available phosphorus; $\mathrm{K}=$ available potassium

The amount of phosphorus absorbed by spring maize plants was lower than that of nitrogen and potassium. Applying phosphate fertilizer to soil can result in the accumulation of high concentrations of phosphorus in surface soils which cannot be 
effectively converted into plant-available forms of phosphorus (Turtola et al., 1999). At different growth stages in nano-biochar amended soil, the phosphorus content of spring maize plants was higher than the control group, indicating nano-biochar can promote phosphorus leaching and the absorption of phosphorus by spring maize roots.

With strong mobility and water solubility of potassium ions in soil, its content is higher than nitrogen and phosphorus. This is why we observed that the accumulation of available potassium was larger than nitrogen and phosphorus in the plant during the growth period of spring maize. However, soil adsorption of potassium ions is poor, so water-soluble potassium ions tend to migrate downward into the soil. Following banding, the nano-biochar adsorbed potassium and the longitudinal migration rate of potassium in the soil decreased, which extended the retention time of potassium in the root soil layer of spring maize.

Spring maize biomass accumulation and yields are closely related to the accumulation of plant nutrients. After the jointing stage, the growth and development of spring maize organs accelerates, and the absorption and accumulation rate of nutrients also greatly increases (Qin et al., 2012). We noted the accumulation of plant nutrients increased continuously throughout the whole growth period. The soil nitrogen and potassium contents were highest at the filling stage, and the soil phosphorus content were highest at the maturation stage. Nutrient accumulation in the spring maize plants was the product of soil nutrient availability and plant biomass requirements. During the spring maize growth period, the nutrient content of crops tended to decline while the nutrient accumulation tended to increase.

Figure 6 summarizes the accumulation of nitrogen, phosphorus and potassium in spring maize plants for each nano-biochar treatment during each spring maize growth period. As shown in Figure 6, plant accumulation of nutrients increased rapidly after the shooting stage, the accumulation of nitrogen and potassium were highest at the filling stage, and the accumulation of phosphorus was highest at the maturation stage. In each growth stage, nano-biochar had a significant effect on the absorption of nutrients in spring maize, with the greatest accumulation of nutrients associated with $0.7 \%$ and $1 \%$ nano-biochar treatments.

\section{The effects of nano-biochar on spring maize growth and yield}

Table 4 shows the effects of nano-biochar contents on growth indicators of spring maize in every growth stage. As shown in Table 4, in the plots with higher nano-biochar content, the plant height, stem diameter and leaf area of spring maize $(0.7 \%$ and $1 \%)$ were significantly higher than those in the control group in the same growth stage. Over the spring maize life-cycle, the plant height and leaf area increased, but the basal stem diameter first increased and then decreased. This was attributed to the vigorous growth of spring maize at the shooting stage when a large amount of water was absorbed by the roots and transported upward. During this time, spring maize was more inclined to radial development, which weakened the horizontal growth.

Table 5 shows the effects of nano-biochar content on maize yields. Based on Table 5, there was a significant correlation between the 1000-grain weight, yield and different nano-biochar contents; the P-value was less than 0.01 , indicating that the application of nano-carbon in the soil has an important effect on maize yield. The plots with higher nano-biochar content $(0.7 \%$ and $1 \%)$ had significantly greater 1000 -grain weight and yield than the control. Compared with the control group, the yield of $0.7 \%$ and $1 \%$ nano-biochar treatment plots were $4.4 \%$ and $5.7 \%$ greater, respectively. 

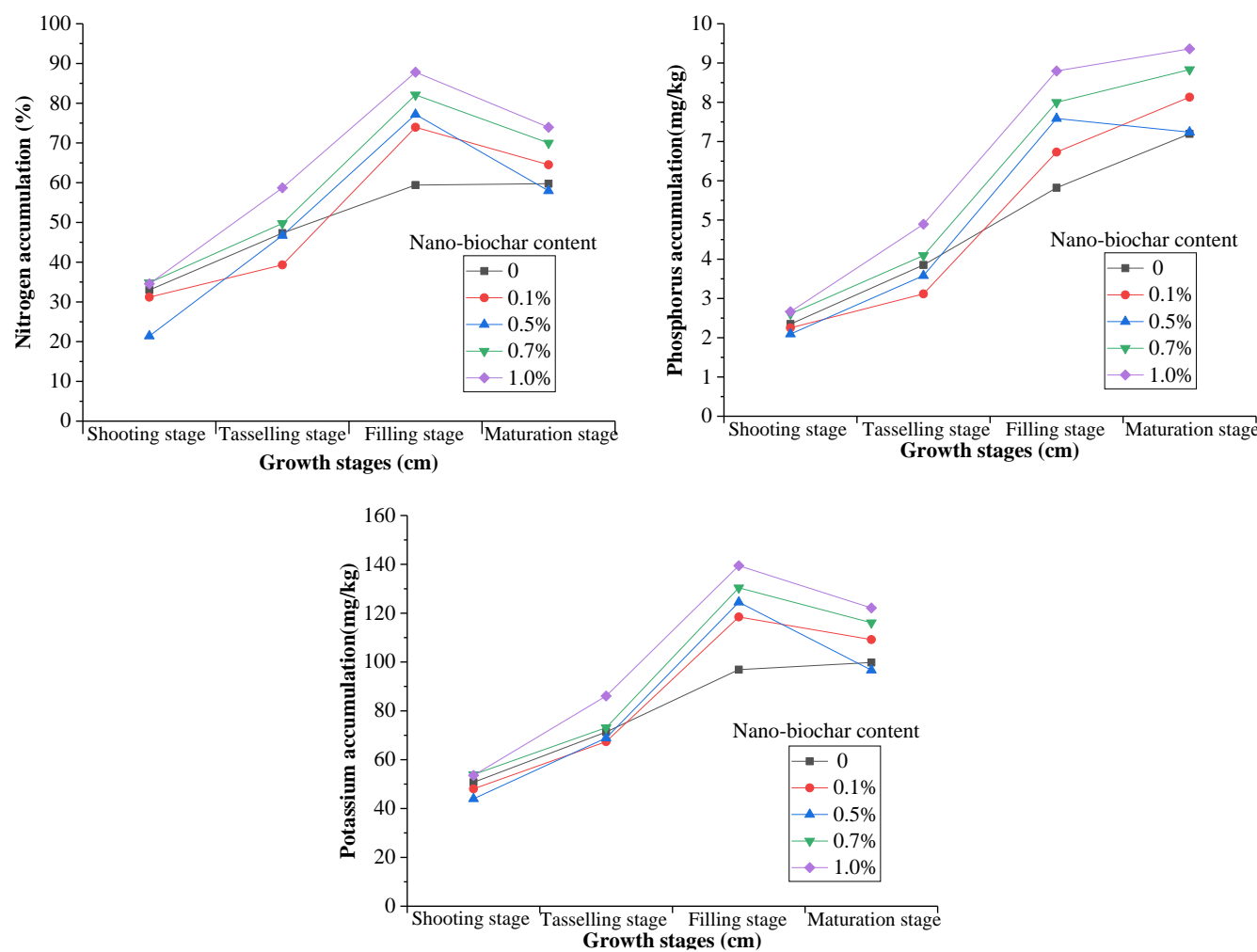

Figure 6. The influence of nano-biochar contents on nutrient accumulation in spring maize

Table 4. The influence of nano-biochar content on spring maize growth indices

\begin{tabular}{|c|c|c|c|c|c|c|}
\hline \multirow{2}{*}{$\begin{array}{l}\text { Nano- } \\
\text { biochar } \\
\text { content }\end{array}$} & \multirow{2}{*}{$\begin{array}{l}\text { Measurement } \\
\text { variables }\end{array}$} & \multicolumn{5}{|c|}{ Growth stages } \\
\hline & & Seedling stage & Shooting stage & Tasselling stage & Filling stage & Maturation stage \\
\hline \multirow{4}{*}{0} & Plant height $/ \mathrm{cm}$ & $46.2 \pm 1.1 \mathrm{~b}$ & $90.3 \pm 2.2 b$ & $168.4 \pm 2.7 \mathrm{c}$ & $188.4 \pm 5.4 b$ & $226.7 \pm 3.9 \mathrm{a}$ \\
\hline & Stem diameter $/ \mathrm{cm}$ & $1.98 \pm 0.291 b$ & $3.62 \pm 0.155 \mathrm{a}$ & $6.77 \pm 0.148 b$ & $7.04 \pm 0.088 \mathrm{~b}$ & $6.83 \pm 0.236 \mathrm{a}$ \\
\hline & Leaf area $/ \mathrm{cm}^{2}$ & $45.3 \pm 1.2 \mathrm{~b}$ & $882.4 \pm 11.4 \mathrm{c}$ & $4654.8 \pm 21.3 \mathrm{c}$ & $5763.9 \pm 23.1 \mathrm{c}$ & $5614.2 \pm 38.2 \mathrm{c}$ \\
\hline & Biomass /g & $3.12 \pm 0.141 \mathrm{c}$ & $21.7 \pm 3.52 \mathrm{~b}$ & $75.2 \pm 8.67 \mathrm{~b}$ & $221.6 \pm 17.33 \mathrm{c}$ & $398.3 \pm 23.23 \mathrm{c}$ \\
\hline \multirow{4}{*}{$0.1 \%$} & Plant height /cm & $45.4 \pm 2.4 \mathrm{~b}$ & $92.3 \pm 3.2 \mathrm{a}$ & $170.4 \pm 8.2 b$ & $190.5 \pm 7.3 b$ & $224.3 \pm 6.4 b$ \\
\hline & Stem diameter $/ \mathrm{cm}$ & $2.03 \pm 0.208 \mathrm{a}$ & $3.58 \pm 0.232 \mathrm{a}$ & $6.81 \pm 0.313 \mathrm{a}$ & $7.01 \pm 0.283 b$ & $6.78 \pm 0.426 b$ \\
\hline & Leaf area $/ \mathrm{cm}^{2}$ & $47.1 \pm 3.0 \mathrm{a}$ & $891.1 \pm 23.0 \mathrm{~b}$ & $4668.5 \pm 41.7 b$ & $5784.1 \pm 37.5 b$ & $5598.5 \pm 55.1 \mathrm{c}$ \\
\hline & Biomass /g & $3.21 \pm 0.523 b c$ & $20.8 \pm 2.031 \mathrm{~b}$ & $77.3 \pm 5.051 \mathrm{~b}$ & $225.9 \pm 9.142 \mathrm{c}$ & $404.6 \pm 18.216 \mathrm{c}$ \\
\hline \multirow{4}{*}{$0.5 \%$} & Plant height $/ \mathrm{cm}$ & $47.1 \pm 1.4 \mathrm{a}$ & $92.4 \pm 3.3 \mathrm{a}$ & $172.4 \pm 1.5 b$ & $193.3 \pm 2.6 \mathrm{a}$ & $228.3 \pm 1.9 \mathrm{a}$ \\
\hline & Stem diameter $/ \mathrm{cm}$ & $2.111 \pm 0.152 \mathrm{a}$ & $3.66 \pm 0.206 \mathrm{a}$ & $6.84 \pm 0.236 \mathrm{a}$ & $7.05 \pm 0.218 b$ & $6.88 \pm 0.134 \mathrm{a}$ \\
\hline & Leaf area $/ \mathrm{cm}^{2}$ & $47.5 \pm 1.5 \mathrm{a}$ & $895.8 \pm 28.7 b$ & $4685.3 \pm 52.5 b$ & $5804.2 \pm 41.3 b$ & $5645.6 \pm 62.1 b$ \\
\hline & Biomass /g & $3.44 \pm 0.116 b$ & $22.6 \pm 2.48 \mathrm{a}$ & $76.8 \pm 5.73 b$ & $232.6 \pm 8.14 b$ & $415.6 \pm 14.74 b$ \\
\hline \multirow{4}{*}{$0.7 \%$} & Plant height $/ \mathrm{cm}$ & $46.8 \pm 1.9 \mathrm{a}$ & $93.1 \pm 3.8 \mathrm{a}$ & $173.9 \pm 5.9 \mathrm{~b}$ & $195.6 \pm 7.8 \mathrm{a}$ & $231.7 \pm 7.2 \mathrm{a}$ \\
\hline & Stem diameter $/ \mathrm{cm}$ & $2.08 \pm 0.217 \mathrm{a}$ & $3.64 \pm 0.276 \mathrm{a}$ & $6.86 \pm 0.259 a$ & $7.1 \pm 0.393 \mathrm{a}$ & $6.84 \pm 0.308 \mathrm{a}$ \\
\hline & Leaf area $/ \mathrm{cm}^{2}$ & $48.2 \pm 3.0 \mathrm{a}$ & $904.6 \pm 33.1 b$ & $4705.9 \pm 67.9 b$ & $5844.3 \pm 52.4 \mathrm{a}$ & $5714.9 \pm 71.7 \mathrm{a}$ \\
\hline & Biomass /g & $3.73 \pm 0.033 \mathrm{a}$ & $22.7 \pm 1.025 \mathrm{a}$ & $80.1 \pm 3.032 \mathrm{a}$ & $241.1 \pm 7.208 \mathrm{a}$ & $421.8 \pm 6.316 b$ \\
\hline \multirow{4}{*}{$1 \%$} & Plant height $/ \mathrm{cm}$ & $48.6 \pm 2.1 \mathrm{a}$ & $95.2 \pm 4.7 \mathrm{a}$ & $176.4 \pm 6.4 \mathrm{a}$ & $196.5 \pm 5.2 \mathrm{a}$ & $233.7 \pm 8.7 \mathrm{a}$ \\
\hline & Stem diameter $/ \mathrm{cm}$ & $2.15 \pm 0.203 \mathrm{a}$ & $3.7 \pm 0.337 \mathrm{a}$ & $6.91 \pm 0.361 \mathrm{a}$ & $7.14 \pm 0.644 a$ & $6.94 \pm 0.776 \mathrm{a}$ \\
\hline & Leaf area $/ \mathrm{cm}^{2}$ & $49.9 \pm 3.2 \mathrm{a}$ & $918.7 \pm 15.8 \mathrm{a}$ & $4745.2 \pm 44.2 \mathrm{a}$ & $5865.8 \pm 83.3 \mathrm{a}$ & $5725.8 \pm 65.5 \mathrm{a}$ \\
\hline & Biomass /g & $3.8 \pm 0.119 \mathrm{a}$ & $23.5 \pm 1.445 \mathrm{a}$ & $81.4 \pm 4.628 \mathrm{a}$ & $245.3 \pm 2.53 \mathrm{a}$ & $430.4 \pm 8.97 \mathrm{a}$ \\
\hline
\end{tabular}

' \pm ' = standard deviation. There is no significant difference at 0.05 level in the same column of data with the same letters (Duncan's method) 
Table 5. The yield of spring maize in every plot

\begin{tabular}{c|c|c}
\hline Nano-biochar content & 1000-grain weight $\mathbf{( g )}$ & Yield $\mathbf{( k g \cdot \mathbf { h m } ^ { - 2 } )}$ \\
\hline 0 & 252.4 & 4836.25 \\
$0.1 \%$ & 250.3 & 4853.18 \\
$0.5 \%$ & 261.1 & 4908.68 \\
$0.7 \%$ & 266.8 & 5047.42 \\
$1 \%$ & 274.9 & 5112.88 \\
p-value & $9.55 \times 10^{-12}$ & $2.51 \times 10^{-13}$ \\
\hline
\end{tabular}

\section{Conclusion}

The study tested different rates of nano-biochar application and analyzed the subsequent effects on physical and chemical properties of soil, soil water characteristics, fertilizer use and growth characteristics of spring maize in the field. The results indicated that banding nano-biochar in the root zone slightly increased soil bulk density. Amending soil with nano-biochar increased soil aggregates with the soil particle size > $2 \mathrm{~mm}$ from 0.69 to $37.12 \%$, and nano-biochar application rates of $0.7 \%$ and $1 \%$ had the greatest effects on improving soil water-stable aggregates. The band of nano-biochar in the soil inhibited the movement of soil moisture to the deep soil and decreased evapotranspiration. It also improved nutrient retention and delayed the leaching of nitrogen, phosphorus and potassium in soil. Nano-biochar also prompted spring maize uptake of soil nutrients. Maize grown in soil amended with nano-biochar had significantly greater plant height, stem diameter and leaf area than those grown in soils without nano-biochar. The plot with the highest nano-biochar contents $(0.7 \%$ and $1 \%)$ has the greatest 1000-grain weights and yields. Compared with the control group, the yields of $0.7 \%$ and $1 \%$ nano-biochar were increased by $4.4 \%$ and $5.7 \%$, respectively. Nano-biochar has an obvious effect on soil improvement and crop growth, but its application is slightly complicated. In order to promote the large-scale popularization of this method on Loess Plateau, how to simplify the method is still the key problem we should consider.

Acknowledgments. This study was funded by the National Natural Science Foundation of China (41977007 ; 41830754 ; 41807131), Research project of State Key Laboratory of Eco-hydraulics in Northwest Arid Region of China (2019KJCXTD-4 ; QJNY-2019-01).

\section{REFERENCES}

[1] Ahmed, F., Arthur, E., Plauborg, F., et al. (2018): Biochar amendment of fluvio-glacial temperate sandy subsoil: effects on maize water uptake, growth and physiology. - Journal of Agronomy and Crop Science 204(2): 123-136.

[2] Albiter, M. A., Crooks, R. M., Zaera, F., et al. (2010): Adsorption of carbon monoxide on dendrimer-encapsulated platinum nanoparticles: liquid versus gas phase. - The Journal of Physical Chemistry Letters 1(1): 38-40.

[3] Arif, M., Ilyas, M., Riaz, M., et al. (2017): Biochar improves phosphorus use efficiency of organic-inorganic fertilizers, maize-wheat productivity and soil quality in a low fertility alkaline soil. - Field Crops Research 214: 25-37.

[4] Bossuyt, H., Denef, K., Six, J., et al. (2001): Influence of microbial populations and residue quality on aggregate stability. - Applied Soil Ecology 16(3): 195-208. 
[5] Dempster, D. N, Jones, D. L, Murphy, D. V. (2012): Clay and biochar amendments decreased inorganic but not dissolved organic nitrogen leaching in soil. - Soil Research 50(3): 216-221.

[6] Dong, X., Guan, T., Li, G., et al. (2016): Long-term effects of biochar amount on the content and composition of organic matter in soil aggregates under field conditions. Journal of Soils and Sediments 16(5): 1481-1497.

[7] Fan, J., Yu, G., Wang, Q., et al. (2014): Mulching effects on water storage in soil and its depletion by alfalfa in the loess plateau of northwestern China. - Agricultural Water Management 138: 10-16.

[8] Fu, Z., Wang, Y., An, Z. (2015): Spatio-temporal characteristics of soil bulk density and saturated hydraulic conductivity at small watershed scale on loess plateau. - Transactions of the Chinese Society of Agricultural Engineering 31(13): 128-134 (in Chinese).

[9] Guo, Y., Li, Y., Zhu, T., Ye, M. (2013): Effects of concentration and adsorption product on the adsorption of $\mathrm{SO}_{2}$ and NO on activated carbon. - Energy Fuels 27(1): 360-366.

[10] Han, F., Zheng, J., Hu, W., et al. (2010): Spatial variability and distribution of soil nutrients in a catchment of the loess plateau in china. - Acta Agriculturae Scandinavica, Section B - Plant Soil Science 60(1): 48-56.

[11] Itabari, J. K., Gregory, P. J., Jones, R. K. (1993): Effects of temperature, soil water status and depth of planting on germination and emergence of maize (Zea mays) adapted to semi-arid eastern Kenya. - Experimental Agriculture 29(3): 351-364.

[12] Jia, Y. H., Shao, M. A., Jia, X. X. (2013): Spatial pattern of soil moisture and its temporal stability within profiles on a loessial slope in northwestern China. - Journal of Hydrology 495: 150-161.

[13] Liang, B., Lehmann, J., Solomon, D., et al. (2006): Black carbon increases cation exchange capacity in soils. - Soil Science Society of America Journal 70(5): 1719.

[14] Liu, J., Schulz, H., Brandl, S., et al. (2012a): Short-term effect of biochar and compost on soil fertility and water status of a dystric cambisol in NE Germany under field conditions. - Journal of Plant Nutrition and Soil Science 175(5): 698-707.

[15] Liu, Y., Fu, B., Yihe Lü, et al. (2012b): Hydrological responses and soil erosion potential of abandoned cropland in the Loess Plateau, China. - Geomorphology 138(1): 0-414.

[16] Liu., Y. L., Zhou, B. B., Z., Wang, Q. J., et al. (2015): Effects of nano-carbon on water movement and solute transport in loessial soil. - Journal of Soil and Water Conservation 29(1): 21-25 (in Chinese).

[17] Manivasakan, P., Karunakaran, G., Yuvakkumar, R., et al. (2013): Effect of nanosilica and silicon sources on plant growth promoting rhizobacteria, soil nutrients and maize seed germination. - IET Nanobiotechnology 7(3): 70-77.

[18] Mesarič, T., Baweja, L., Drašler, B., et al. (2013): Effects of surface curvature and surface characteristics of carbon-based nanomaterials on the adsorption and activity of acetylcholinesterase. - Carbon 62: 222-232.

[19] Novak, J. M., Lima, I., Xing, B. S., et al. (2009): Characterization of designer biochar produced at different temperatures and their effects on a loamy sand. - Annals of Environmental Science 3: 195-206.

[20] Ouyang, L., Wang, F., Tang, J., et al. (2013): Effects of biochar amendment on soil aggregates and hydraulic properties. - Journal of Soil Science and Plant Nutrition 13(4): 991-1002.

[21] Petr, K., Bernd, S., Astrid, R., et al. (2011): Citramalic acid and salicylic acid in sugar beet root exudates solubilize soil phosphorus. - BMC Plant Biology 11(1): 121.

[22] Qin, X., Liu, K., Zhou, S. L. (2012): Studies on characteristics of nitrogen absorption and utilization under water-saving cultivation in winter wheat region of north china plain. Journal of Agricultural Science Technology, pp. 96-101 (in Chinese).

[23] Reese, C. L., Clay, D. E., Clay, S. A., et al. (2014): Winter cover crops impact on corn production in semiarid regions. - Agronomy Journal 106(4): 1479-1488. 
[24] Rens, H., Bera, T., Alva, A. K. (2018): Effects of biochar and biosolid on adsorption of nitrogen, phosphorus, and potassium in two soils. - Water, Air, and Soil Pollution 229(8): 281. https://doi.org/10.1007/s11270-018-3925-8.

[25] Roy, J. L., Mcgill, W. B. (2000): Flexible conformation in organic matter coatings: an hypothesis about soil water repellency. - Canadian Journal of Soil Science 80(1): 143152.

[26] Sharma, R., Bell, R. W., Wong, M. T. F. (2015): Phosphorus forms in soil solution and leachate of contrasting soil profiles and their implications for P mobility. - Journal of Soils and Sediments 15(4): 854-862.

[27] Shukla, J., Maldar, N. N., Sharon, M., et al. (2012): Synthesis of carbon nano material from different parts of maize using transition metal catalysts. - Der Chemica Sinica 10581070.

[28] Six, J., Bossuyt, H., Degryze, S., et al. (2004): A history of research on the link between (micro)aggregates, soil biota, and soil organic matter dynamics. - Soil and Tillage Research 79(1): 7-31.

[29] Tan, S., Zhou, B., Wang, Q. (2016): Effects of nanocarbon on the hydraulic parameters and the solute transport process for disturbed loessial soil. - Arabian Journal of Geosciences 9(1): 4.

[30] Turtola, E., Yli-Halla, M. (1999): Fate of phosphorus applied in slurry and mineral fertilizer: accumulation in soil and release into surface runoff water. - Nutrient Cycling in Agroecosystems 55(2): 165-174.

[31] Vacher, C. A., Loch, R. J., Raine, S. R., et al. (2003): Effect of polyacrylamide additions on infiltration and erosion of disturbed lands. - Australian Journal of Soil Research 41(8): 1509.

[32] Wang, Y., Hu, W., Zhu, Y., et al. (2015): Vertical distribution and temporal stability of soil water in $21-\mathrm{m}$ profiles under different land uses on the Loess Plateau in China. Journal of Hydrology 527: 543-554.

[33] Wang, Y., Han, Z., Zhang, Z., et al. (2016): Biochar application promote growth parameters of soybean and reduces the growth difference. - Communications in Soil Science and Plant Analysis 47(12): 1493-1502.

[34] Zhang, J. H., Liu, J. L., Zhang, J. B., et al. (2010): Effects of nitrogen application rates on translocation of dry matter and nitrogen utilization in rice and wheat. - Acta Agronomica Sinica 36(10): 1736-1742.

[35] Zhou, B. B., Chen, X. P., Lü, J., et al. (2017): Inhibiting effect of nano-carbon on rainfall erosion of different vegetation cover on loess slope land. - Transactions of the Chinese Society of Agricultural Engineering 33(2): 116-124 (in Chinese).

[36] Zhou, B. B., Chen, X. P., Wang, Q. J., et al. (2018): Effects of nano carbon on soil erosion and nutrient loss in a semi-arid loess region of Northwestern China. International Journal of Agricultural Biological Engineering 11(1): 138-145. 